\title{
Monitoring the Effects of Tunnelling Under an Existing Tunnel- Fibre Optics
}

\author{
C.Y. Gue, M. Wilcock, M.M. Alhaddad, M.Z.E.B. Elshafie, K. Soga, R. J. Mair \\ University of Cambridge, Cambridge, Cambridgeshire, United Kingdom
}

\begin{abstract}
Underground tunnel networks are at the heart of United Kingdom's infrastructure, carrying more than 1,100 million passengers each year along its 249 miles long network via 11 underground lines, serving 270 stations. With a complex existing underground rail network already in place; it is inevitable that new tunnels will be constructed within close proximity to existing tunnels. At London Liverpool Street Station, the new eastbound Crossrail platform tunnel was constructed underneath the existing Royal Mail Tunnel at a parallel alignment over a length of over $100 \mathrm{~m}$ with a clear distance of less than $2 \mathrm{~m}$ separating the two. Fibre optic strain sensing system based on Brillouin Optical Time Domain Reflectometry (BOTDR) was installed to measure continuous strain profiles of the cast iron linings of Royal Mail Tunnel. This has provided valuable insights to the deformation mechanisms both during the pilot and final tunnel enlargement.
\end{abstract}

\section{INTRODUCTION}

\subsection{Problem}

In a congested urban environment, tunnelling often takes place in close proximity to existing structures such as buildings, pipelines and other existing tunnels. Constructing a new tunnel underneath an existing tunnel will impose additional stresses and strains on the latter. It becomes the responsibility of the design and construction team to ensure that these adverse effects are kept within acceptable limits by introducing appropriate mitigation measures. Without a proper understanding of the behaviour of the existing tunnel when it is subjected to tunnelling works underneath it would be difficult to design efficient mitigation works, which could potentially lead to significant project cost. In this paper, a case study is presented in which distributed fibre optic strain sensing technology was used to monitor the deformation behavior of an existing tunnel (Royal Mail tunnel) when a new tunnel (Crossrail) was being constructed underneath.

\subsection{Background of the existing Royal Mail Tunnel}

Completed in 1917, the Royal Mail Tunnel was the world's first driverless electric underground railway used to convey mail from eastern to western sorting offices in London. It stretches for $10.5 \mathrm{~km}$ and when it was in full operation (tunnel operations were ceased in 2003), it was serving 8 stations, carrying 12 million postal items daily on its line. The tunnel, which has an internal diameter of $2.743 \mathrm{~m}$, was constructed within the London Clay formation at a depth of approximately $27 \mathrm{~m}$ below ground level. The tunnel lining was made of cast iron rings with each ring consisting of seven segments bolted together.

\subsection{Crossrail at London Liverpool Street Station}

Underground transport tunnel networks are an essential part of the UK's infrastructure. Crossrail is a new $21 \mathrm{~km}$ addition to London's Underground network which connects Maidenhead and Heathrow to the west of London with Shenfield and Abbey Wood to the east. Upon completion, Crossrail will increase London's rail capacity by $10 \%$.

At Liverpool Street Station, in central London, the new eastbound Crossrail platform tunnel, approximately $11 \mathrm{~m}$ in diameter, was, constructed using sprayed concrete lining (SCL). The Crossrail tunnel was constructed directly underneath the existing Royal Mail Tunnel, in a parallel direction, with only a clear distance of about $2 \mathrm{~m}$ between the two. This is shown schematically in Figure 1.

Assessments were carried out on the impact of the ground movements resulting from the Crossrail works on the Royal Mail tunnel. One of the outcomes from the assessment was that the tunnelling works would cause the existing tunnel to deform; however, there was considerable uncertainty about the likely mode of deformation. Hence, tunneling underneath the existing Royal Mail tunnel provided an excellent opportunity to investigate the 
behaviour of cast iron tunnels when subjected to tunneling-induced ground movements. A wide range of instrumentation techniques was used to monitor the Royal Mail tunnel, which collectively provided important insights into its behavior. This paper focuses only on distributed fibre optic strain sensing.

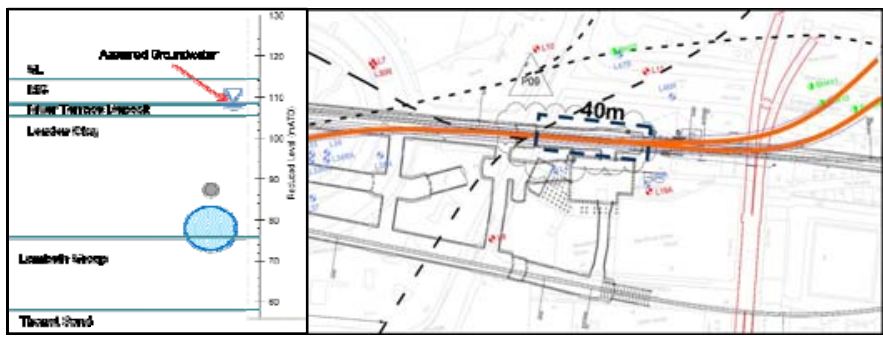

Figure 1. Section and plan view of both tunnels at London Liverpool Street Station.

\section{FIBRE OPTICS INSTRUMENTATION}

\subsection{Principles of Brillouin Optical Time Domain Reflectometry (BOTDR)}

Conventional instrumentation usually consists of multiple discrete point measurements over an entire system. The ambiguity of the interpolated data between these points presents a major drawback in terms of fully understanding the response of the system.

Fibre optic strain sensing technology capitalises on the capability of light waves to travel along the entire length of a cable and the strain-dependent frequency shift of the backscattered light to provide a continuous and distributed strain sensing solution (Mohammed, 2008).

As light passes through a fibre optic cable, a small amount of signal will be reflected back to the source as backscattered light. Backscatter within the Brillouin spectrum experiences a linear shift when strain is induced. A BOTDR analyser is able to measure the shift of the peak frequencies as well as the time taken for the backscatter to return to the analyser. This enables the exact location and magnitude of strain to be determined along the entire length, effectively transforming the fibre optic cable into a fully distributed strain sensor.

\subsection{Fibre Optics Cable Layout}

A $40 \mathrm{~m}$ section of the Royal Mail tunnel was instrumented with Hitachi single core tight buffered fibre optic cable. The section comprises of 5 cross sectional attachments, $10 \mathrm{~m}$ apart, and a longitudinal section across the crown as shown in Figure 2. Cross sectional cables were attached directly onto the flanges of the cast iron lining via Araldite 2021 epoxy while the longitudinal cables were attached via L-shaped brackets which were bolted on the flanges on each ring along the instrumented section.
Pretension was applied for the longitudinal section before application of epoxy, in order to capture the compressive strains.

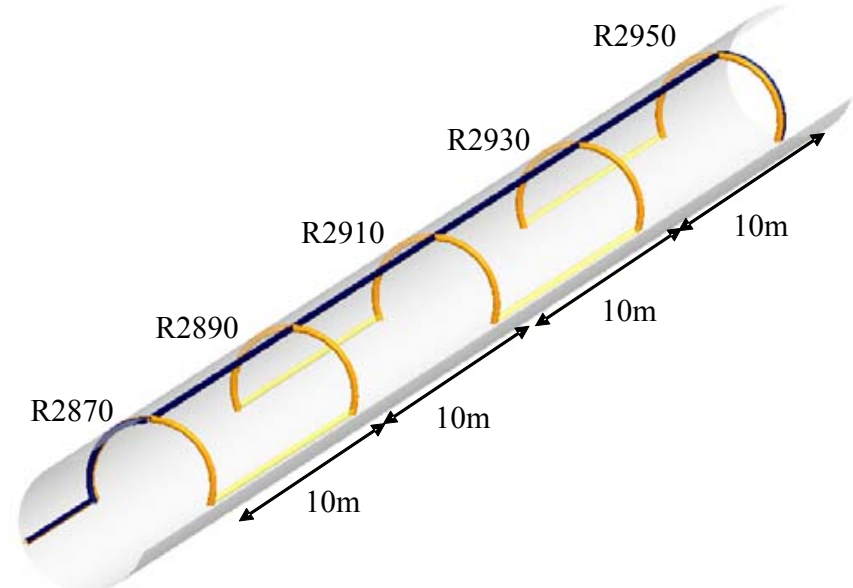

Figure 2. Layout of fibre optic cable instrumentation in Royal Mail Tunnel with cast iron ring numbers.

The entire section of the instrumented tunnel was monitored with a single continuous fibre optic cable. At the end of the instrumented section, the Hitachi fibre optic cable was connected to an extension cable that enabled measurements to be taken at ground surface approximately $200 \mathrm{~m}$ away. The Yokogawa AQ8603 optical fibre strain analyser, located at ground surface on the access shaft to the tunnel, was used to record the measurements during construction of the Crossrail tunnel. This meant that no electrical power was required within the Royal Mail tunnel itself throughout the monitoring duration. The analyser had a spatial resolution of 1 $m$ with the readout resolution set every $5 \mathrm{~cm}$.

A picture of the completed setup is shown in Figure 3 . The fibre optic cable is highlighted in the picture for clarity as the width of the cable is only $0.9 \mathrm{~mm}$; this is an added advantage as it would not obstruct any tunnel operations if required.

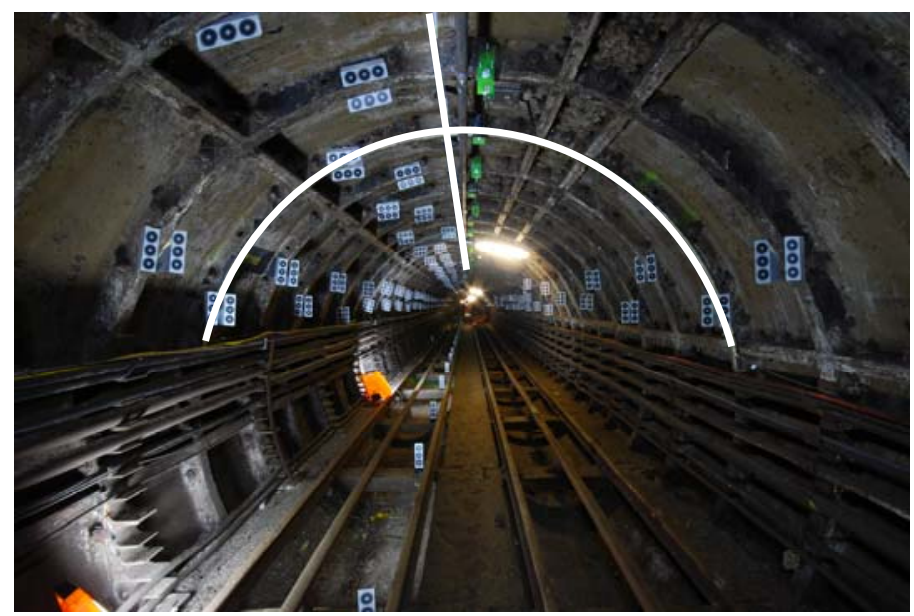

Figure 3. Completed instrumentation layout in Royal Mail Tunnel where Hitachi single core tight buffered cable is highlighted. 
The picture in Figure 3 also shows the other instrumentation systems which were installed by the Centre for Smart Infrastructure Cambridge (CSIC) research group from the University of Cambridge to capture various different behaviours of the Royal Mail tunnel.

As with any strain measurement system, temperature will have an effect on fibre optic cables due to thermal expansion or contraction. In order to compensate for this, temperature cable (EXCEL OS1 8 core 9/125 Loose Tube) was also installed along the length of the monitored section of the tunnel. In contrast with the Hitachi single core tight buffered cable, the temperature cable consists of 8 fibre optic cable cores suspended in a gel-filled tube.

This ensures that no mechanical strain is imposed on the fibre optic cores such that the only strains measured are due to temperature change. This allows temperature compensation to be conducted on the strain measurements in order to obtain the imposed mechanical strains.

It is important to note that the aim of this instrumentation is to measure additional strains that are induced due to the construction of the new platform tunnel below it. Therefore, relative strains (denoted as delta strains in figures) rather than absolute are of interest. Baseline measurements were taken on the $16^{\text {th }}$ of April 2013 and the relative strains were obtained from the difference between subsequent measurements and the baseline.

\section{DATA INTERPRETATION}

\subsection{Cross Sectional Strains}

Continuous monitoring was carried out from $16^{\text {th }}$ of April 2013 to $14^{\text {th }}$ of March 2014; over a period of 11 months. For clarity, data from three stages are presented in Figure 4, namely the early stage, effects from the construction of the pilot tunnel (approximately $6 \mathrm{~m}$ in diameter) and the tunnel enlargement.

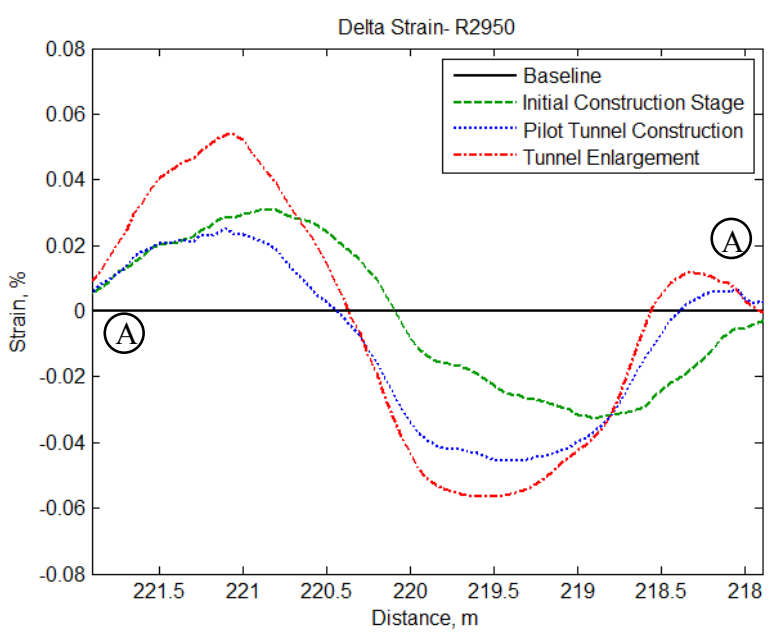

Figure 4. Delta strain plot for ring R2950 at various construction stages.
Figure 4 shows the behaviour in strain for the top half of the cast iron tunnel ring 2950 (location and orientation of the ring is shown in Figure 5).

During the initial construction stages in late July of 2013, an access passage was constructed between the east and westbound platform tunnels. This was located at an offset to the bottom left of the Royal Mail tunnel as shown in Figure 5.

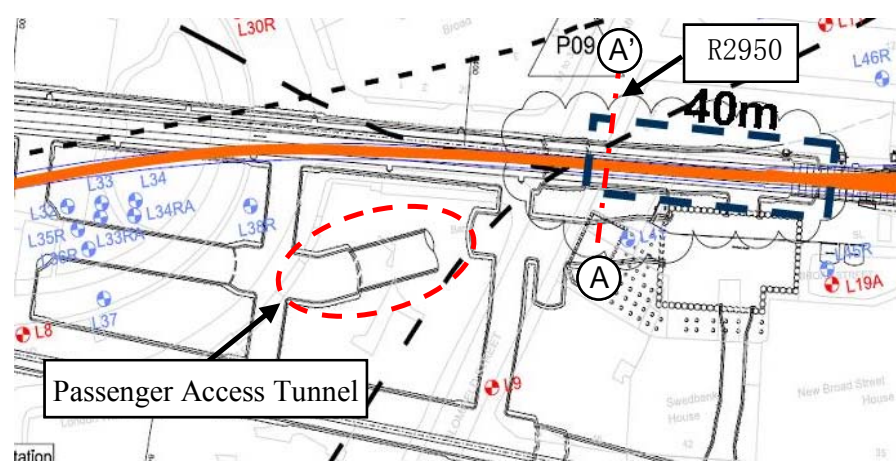

Figure 5. Location of passenger access tunnel in relation to ring R2950.

Due to the soil unloading, the tunnel deformed as a skewed ellipse towards the newly formed cavity; causing tensile strain of the south wall (A) of the tunnel and compressive strain on the northwall (A'). The deformation pattern can be visualised qualitatively as shown in Figure 6.
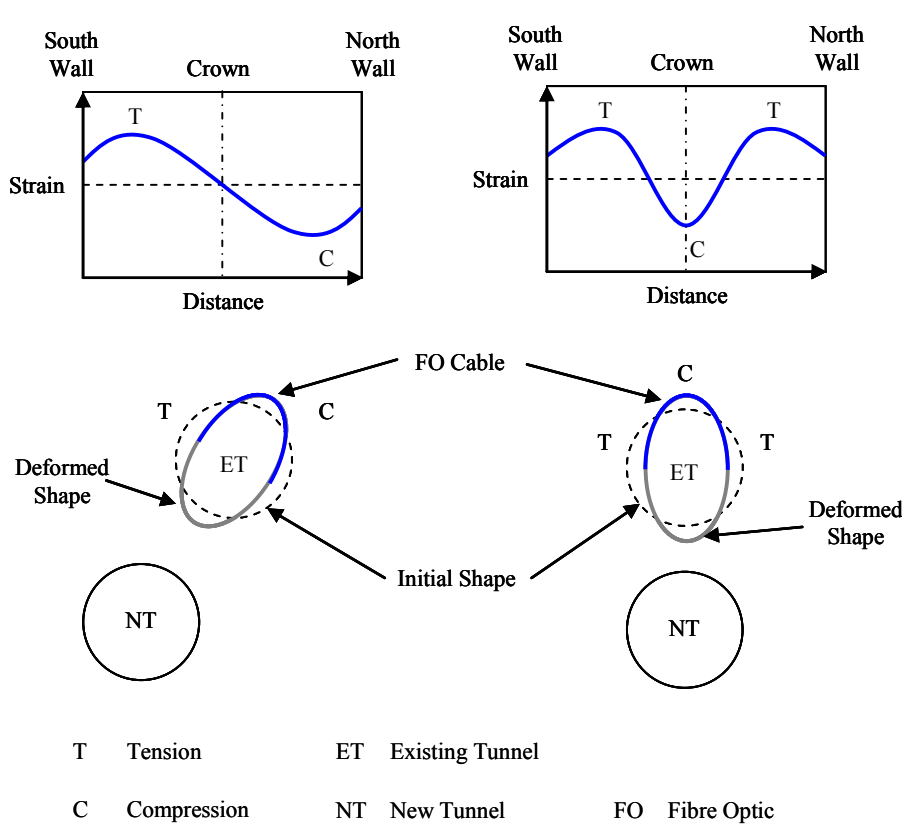

Figure 6. Visualisation of tunnel deformation from fibre optic strain data.

As the pilot tunnel construction progresses in mid of September 2013, to a point below R2950, the ring ovalises vertically with the more dominant strain profile of tension (south wall)-compression (crown)- 
tension (north wall) shown in the dotted line. In line with expectations, the full tunnel enlargement induced higher strain, compared to the pilot tunnel, towards the end of January 2014 when the $11 \mathrm{~m}$ diameter SCL platform tunnel was fully constructed approximately $2 \mathrm{~m}$ below the invert of the Royal Mail tunnel.

The behaviour seen in R2950 was consistently seen on all the other instrumented rings (locations shown in Figure 1) with exception of R2870 where the cable was damaged during installation.

Maximum strains both in tension and compression was in the region of $0.055 \% \varepsilon(550 \mu \varepsilon)$. This value is relatively high if it were to be used directly to infer the stresses on the cast iron sections. Due to the presence of wood packing between each adjoining cast iron sections, and the fixed averaging strain readout of the analyser, the strains measured are the averaged combination of both the strains in the wood packing and cast iron lining.

In order to quantify the exact strains on the cast iron linings, a deconvolution process needs to be carried out with known strains of the wood packing. Unfortunately, local strain gauges across the wood packing were not installed in the tunnel. Nonetheless, the measured strains would still representative of the behavior of the cast iron ring as a whole.

All data presented in this paper are preliminary in nature. Further analyses are currently being undertaken.

\subsection{Longitudinal Section}

In parallel tunnelling, longitudinal strains and settlements of the existing tunnel are of main concern. Strains (and as stresses) need to be within acceptable limits to prevent cracking of the lining while differential settlement has to be controlled, particularly in operational tunnels, to allow for safe train travels along its track.

Longitudinal response of an existing tunnel due to a new tunnel construction directly underneath it is not fully understood. To err on the safe side, design engineers have traditionally chosen to calculate the maximum hogging and sagging deformations based on greenfield settlement profiles along the tunnel invert level (Mair et al, 1993; Taylor, 1995).

However, the mode of deformation will have a significant affect on the calculated extreme fibre stresses (Alhaddad, et al., 2014). The assessment assumes the segments behave rigidly. This allows the tunnel to deform in the bending mode as a single continuous unit.

In segmental lining tunnels, it is not unusual for the bolts linking the rings together to be smaller in diameter than the holes containing them; therefore, it is plausible that such tunnels could deform in a shearing mode, where the rings could slide in relation to each other with less stresses on the bolts and lining. A diagram illustrating the two different deformation modes is shown in Figure 7.

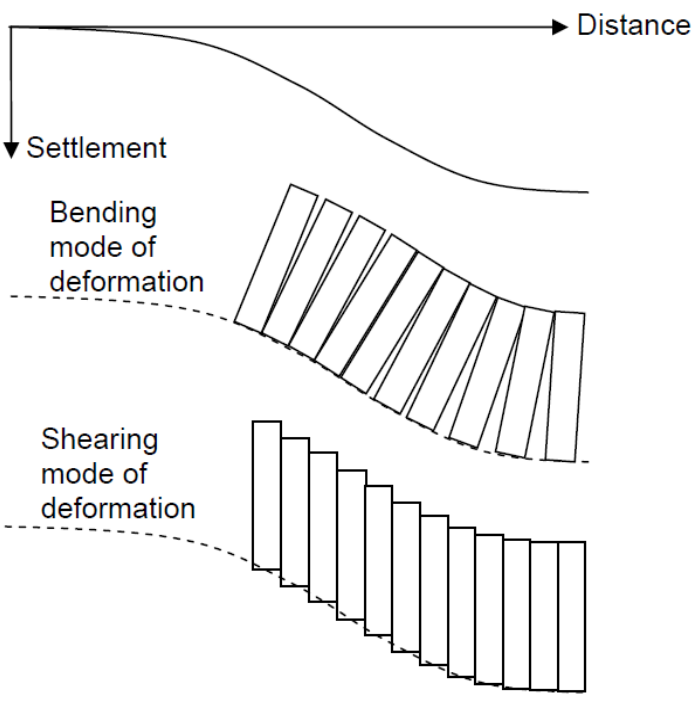

Figure 7. Two plausible modes of deformation for the existing Royal Mail Tunnel (M.Alhaddad et al, 2014).

The fibre optic cables were configured to capture bending strains if the tunnel was deforming in the bending mode only. A separate wireless linear potential differential transformer (LPDT) system was employed to measure the relative shear movements between the cast iron linings.

To help visualise the longitudinal strain data, the change in strain at a particular point is plotted to time (Figure 8). Four locations were selected along the longitudinal section, along the midspan of two adjacent rings.
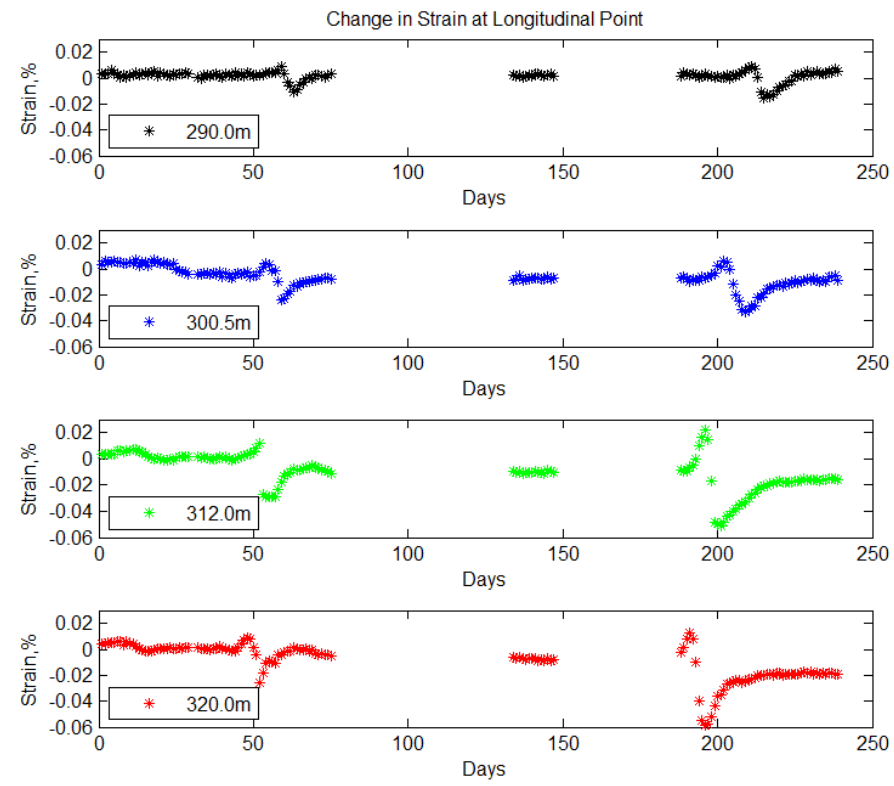

Figure 8. Plot of change in strain for 4 points along the longitudinal section. 
Gaps in the data represent the time when no measurements were taken because there were no construction activities and as such, it did not affect the overall objective of the monitoring scheme.

As the tunnel construction progressed nearer to the points, the red line which was the nearest of the four points to the tunnel construction, observed a change in strains followed suit by the subsequent points in a consistent manner. This was in line with the expected strain "bow wave" trend on the existing tunnel since the eastbound platform tunnel was excavated in parallel to the Royal Mail Tunnel.

The first wave represents the effects of the pilot tunnel while the second was due to the full tunnel enlargement. Similar trends were observed from the automated total station (ATS) readings for the crown settlements recorded separately by the Crossrail construction team.

Magnitude of strain and thus settlement should be identical on every point along the longitudinal section in an ideal case the tunnel is assumed to be uniform and consistent throughout at an infinite length. However, from Figure 8, a slight reduction or damping effect is noticeable towards the east side of the tunnel.

Excavation of a passenger escalator tunnel close to $\mathrm{CH} 390$ would have caused a larger settlement at the western end of the monitored section. As this effect is less prominent with greater distance from the excavation site, this could explain the higher strains and settlements on the western side of the monitored tunnel section.

In addition to that, it is foreseeable that additional structural support was provided by the step plate junction located within $10 \mathrm{~m}$ towards the east of the monitored tunnel section; which splits the tracks into two separate platforms at the station. Hence, the condition of fixity for the tunnel rings nearer to the step plate is different in comparison to the other far end of the monitored tunnel section.

A combination of these two effects reduces the amount of strains and settlement for the rings closer towards the eastern side of the monitored section, in line with the observed trend for both the fibre optics strain sensing system and the ATS.

Further analyses into the pattern of the strain wave revealed a consistent specific trend for each of the pilot and tunnel enlargement at each point on the longitudinal section even though the magnitudes of strains were different.

The data from the fibre optic revealed that the Royal Mail tunnel exhibited a displacement that looks like an inverted $\mathrm{S}$ shape during the construction of both the pilot and tunnel and the enlargement. The S-shaped profile consisted of four critical points: (a) an initial point of effect (b) maximum tension, (c) maximum compression and (d) point of recovery. These are shown schematically in Figure 10.
Similar to the cross sectional data, the magnitude of the measured strains were relatively high, as shown in Figure 8 due to the presence of wood packing between the circumferential joints. As the wood has significantly lower stiffness than that of cast iron, the measured strains shown above are the convoluted strains of both the wood packing and cast iron lining.

\section{CONCLUSIONS}

It has been demonstrated that the fibre optics strain sensing system based on BOTDR has the capabilities to measure full strain profiles of the tunnel lining efficiently.

While the measured strains may not be used directly to interpret the induced stresses on the cast iron lining, it is representative of behavior of entire monitored section as a whole. The observed deformation mechanism is summarised in Figure 9.

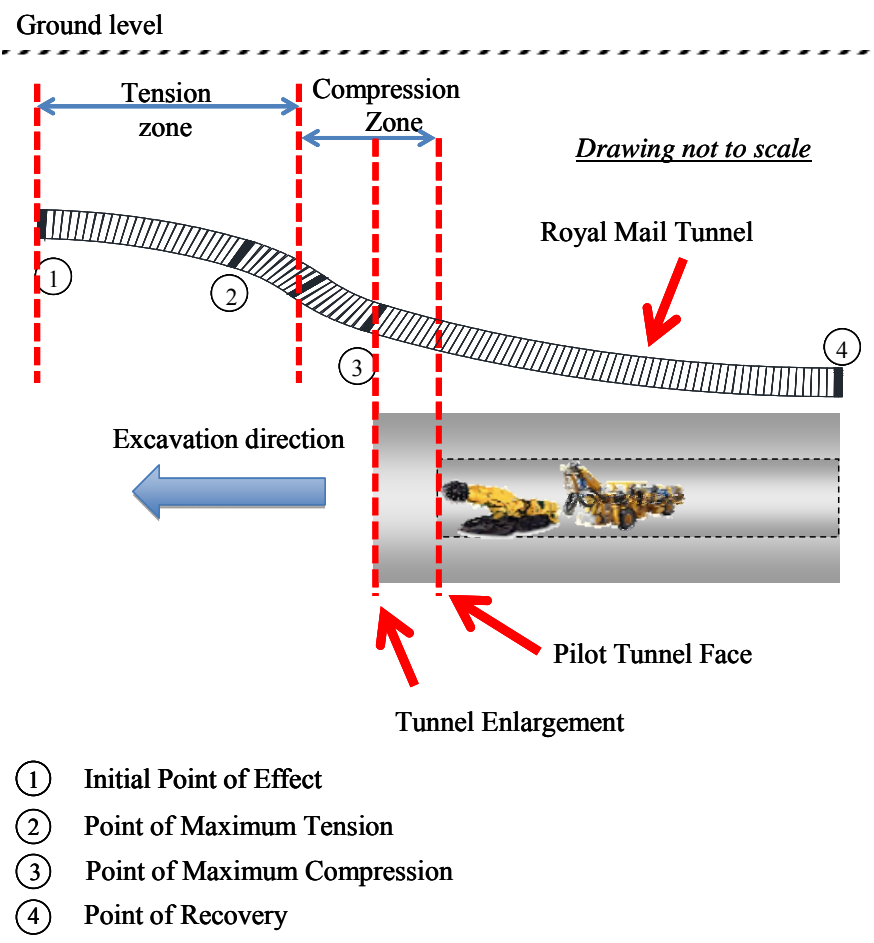

Figure 9. Deformation mechanism of pilot and tunnel enlargement (Not to scale)

This has enabled the longitudinal deformation mechanisms to be observed clearly. Construction of the pilot tunnel has resulted in a much further influence zone ahead of the tunnel face while the enlargement resulted in higher magnitude of strains.

Influence zone behind the face of the tunnel for recovery was relatively similar for both pilot and tunnel enlargement as most of the ground movement has already occurred ahead of the face. Towards the back, the tunnel simply settles and maintains a relatively unstrained state. 
Fibre optic strain data proves that the adverse longitudinal strains are only temporary and will recover at a distance of approximately $5 \mathrm{D}$ beyond the point of interest while the transverse or cross sectional strains are permanent.

The authors acknowledge that the data presented in this paper is preliminary in nature and further research and detailed analyses are currently being carried out.

\section{ACKNOWLEDGEMENTS}

This project would not have been possible without the financial support from Laing O'Rourke Plc who has funded the first author's $\mathrm{PhD}$ studentship in Cambridge. The authors are grateful to the financial, logistical and technical support received from Crossrail (particularly Mike Black and Chris Dulake), Royal Mail, ARUP (particularly Mike Devriendt) and $\mathrm{CH} 2 \mathrm{M}$ Hill (particularly Peter Wright) throughout this project. The authors would also like to acknowledge the significant support of the UK Engineering and Physical Sciences Research Council (EPSRC) and Technology Strategy Board (TSB) for their support through the Cambridge Centre for Smart Infrastructure and Construction (CSIC) in Cambridge.

\section{REFERENCES}

Alhaddad M, Wilcock M, Bevan, H, Gue C, Elshafie M, Soga K, Devriendt M, Waterfall P and Wright P. 2014. Multi suite monitoring of an existing cast iron tunnel subjected to tunnelling induced ground movements. Geo-Shanghai International Conference 2014.

Mair, R. J., Taylor R. N. \& Bracegirdle A. 1993. Subsurface settlement profiles above tunnels in clays. Geotechnique 43, No. 2, 315-320.

Mohammed H. 2008. Distributed optical fibre strain sensing of geotechnical structures. PhD Thesis. Department of Engineering, University of Cambridge.

Taylor R. N. 1995. Tunnelling in soft ground in the UK. Underground construction in soft ground. 123-126. Balkema. 